\title{
EKSTRAK DAUN KEMANGI (Ocimum sanctum) SEBAGAI ANTI SKABIES TERHADAP MARMUT (Cavia porcellus)
}

\author{
Fanny Maulida Junita ${ }^{1}$, Endah Setyaningrum ${ }^{1}$, Sutyarso ${ }^{1}$, Nismah Nukmal ${ }^{1}$ \\ 1'Jurusan Biologi, Fakultas Matematika dan Ilmu Pengetahuan Alam \\ Universitas Lampung
}

[email korespondensi: Fannymjunita@gmail.com]

\begin{abstract}
Basil Leaf Extract (Ocimum sanctum) as an Anti-Scabies Towards Guinea Pigs (Cavia porcellus). Scabies is a disease caused by Sarcoptes Scabiei Mites. Usually scabies attacks humans and animals. Guinea pigs are one of the animals that are often affected by scabies. Basil leaves as medicinal plant contain flavonoid compounds, tannins and essential oils that contain eugenol. Eugenol is an anti-parasitic agent that can inhibit the growth of Sarcoptes scabiei mites. This study aims to determine the effect of basil leaf extract (Ocimum sanctum) on the diameter of a scab caused by Sarcoptes scabies mites. This type of research is experimental research with RAL experimental design (Completely Randomized Design). The treatment was divided into 3 groups i.e negative control $(0.5 \% \mathrm{NaCMC})$, positive control (sufladex), and $100 \%$ basil leaf extract. Treatment and observation carried out for 9 days. Data obtained in the form of a scab diameter were analyzed using One Way ANOVA and results obtained there were differences in the scab diameter $(P>0,000)$. And the results were proceed with the Fisher LSD (Least Significance Different) test. Results showed that basil leaf extract had the lowest diameter of scab.
\end{abstract}

Keywords: Guinea pigs, Scabies, Basil leaf extract.

\section{Abstrak : Ekstrak Daun Kemangi (Ocimum sanctum) Sebagai Anti Skabies Terhadap Marmut (Cavia porcellus).}

Skabies merupakan salah satu penyakit yang disebabkan oleh tungau Sarcoptes scabiei. Biasanya skabies menyerang pada manusia dan hewan. Marmut merupakan salah satu hewan yang sering terkena skabies. Daun kemangi sebagai tanaman obat mengandung senyawa flavonoid, tanin dan minyak atsiri yang memiliki kandungan eugenol. Eugenol bersifat sebagai zat anti parasit yang dapat menghambat pertumbuhan tungau Sarcoptes scabiei. Penelitian ini bertujuan untuk mengetahui pengaruh ekstrak daun kemangi (Ocimum sanctum) terhadap diameter keropeng yang disebabkan oleh tungau Sarcoptes scabies. Jenis penelitian adalah penelitian eksperimental dengan rancangan percobaan RAL ( Rancangan Acak Lengkap). Perlakuan dibagi menjadi 3 kelompok yaitu, kontrol negatif (NaCMC $0.5 \%$ ), kontrol positif (sufladex), dan ekstrak daun kemangi $100 \%$. Pemberian perlakuan dan pengamatan dilakukan selama 9 hari. Data yang diperoleh berupa diameter keropeng dianalisis menggunakan One Way ANOVA dan didapatkan hasil terdapat perbedaan diameter keropeng $(P>0,000)$. Kemudian dilanjutkan dengan uji Fisher LSD (Least Significance Different). Hasil menunjukkan ekstrak daun kemangi memiliki diameter keropeng yang paling rendah.

Kata kunci : Marmut, skabies, ekstrak daun kemangi

\section{PENDAHULUAN}

Skabies atau yang disebut dengan gudikan merupakan salah satu penyakit kulit yang dijumpai pada hewan peliharaan ataupun manusia. Biasanya hewan peliharaan yang terinfeksi adalah marmut. Penyakit ini disebabkan oleh infeksi tungau
Sarcoptes scabiei. Tungau Sarcoptes scabiei merupakan ektoparasit yang menyerang hewan ataupun manusia pada bagian kulit. Ada beberapa faktor yang dapat menyebabkan penyakit ini menjadi berkembang antara lain sanitasi lingkungan yang kurang baik, kumuh, kebersihan yang buruk, 
pengetahuan yang kurang, usia, jenis kelamin dan perkembangan demografi (Djuanda, 2010).

Salah satu tumbuhan yang dapat digunakan sebagai obat ialah kemangi (Ocimum sanctum ). Banyak masyarakat belum mengetahui bahwa kemangi telah terbukti mengandung zat aktif. Zat aktif yang terkandung pada kemangi adalah flavonoid, saponin, tanin dan minyak atsiri (Wijayani, 2014). Minyak atsiri pada daun kemangi tersusun dari senyawa aktif berupa eugenol dan methyl clavical dan berfungsi sebagai larvasida (Dattu et al, 2008). Kandungan eugenol pada kemangi berkisar antara $40 \%$ sampai $71 \%$ (Prakash \& Gupta 2004).

\section{METODE}

Penelitian eksperimental dengan rancangan percobaan menggunakan Rancangan Acak Lengkap (RAL). Bahan yang digunakan dalam penelitian ini adalah 27 keropeng terinfeksi Sarcoptes scabiei pada marmut. daun kemangi (Ocimum sanctum), etanol $96 \%$ sebagai pelarut pada proses maserasi, aquades, NaCMC sebagai kontrol negatif, dan obat skabies sebagai kontrol positif.

Pembuatan ekstrak daun kemangi dilakukan dengan menggunakan metode maserasi. Pertama daun kemangi yang diperoleh dibersihkan dengan air mengalir, dan dikeringkan anginkan selama 2 kali 24 jam. Kemudian, daun dimasukkan ke dalam oven selama 2 jam dengan suhu $45^{\circ} \mathrm{C}$.

Daun yang kering dihaluskan menggunakan blender dan diayak untuk mendapatkan serbuk (simplisia). Setelah itu, di masukkan $200 \mathrm{gr}$ simplisia yang dicampur dengan 2 Liter etanol $96 \%$ kedalam beaker glass, dan tutup. Kemudian diamkan selama 1 kali 24 jam.Rendaman simplisia tersebut kemudian disaring menggunkan kertas saring hingga menghasilkan cairan yang terbebas dari simplisia. Kemudian cairan dipekatkan dengan menggunakan alat rotary evaporator degan suhu $49^{\circ} \mathrm{C}$, kecepatan $20 \mathrm{rpm}$ dan tekanan 176 mBar sampai pelarut tidak menetes lagi. Cairan tersebut dapat dikatakan sebagai ekstrak daun kemangi $100 \%$.

Perlakuan pada penelitian dilakukan dengan cara membagi menjadi 3 kelompok, yaitu kontrol negatif diberi perlakuan NaCMC $0.5 \%$, kontrol positif diberi perlakuan dengan obat skabies (sulfadex), dan kelompok perlakuan diberi ekstrak daun kemangi. Pemberian perlakuan ini dilakukan dengan cara penyemprotan pada keropeng yang terinfeksi sebanyak 1 kali sehari selama 9 hari.

Pengamatan pada keropeng dilakukan sehari sekali selama 9 hari perlakuan. Pengamatan ini dilakukan dengan cara mengamati tanda-tanda kesembuhan. Penilaian kesembuhan dilakukan dengan mengukur diameter keropeng menggunakan jangka sorong. Data pengamatan dihitung dan diakumulasikan dengan perangkat software Minitab, kemudian dianalisis dengan menggunakan uji one-way ANOVA, apabila ada perbedaan secara bermakna maka dilanjutkan dengan Uji Fisher LSD (Least Significance Different) dengan taraf signifikan $\mathrm{a}=$ $5 \%$.

\section{HASIL}

\section{Pemeriksaan Keropeng Pada Marmut Secara Mikroskopis}

Berdasarkan hasil pemeriksaan mikroskopis, yang diakukan pada sampel keropeng, menunjukkan adanya tungau Sarcoptes scabiei (Gambar 1). Dengan ciri bentuk tubuh yang membulat, terdapat duri, pulvilli, kaki dan kepala. Hasil identifikasi tersebut sesuai dengan buku Veterinary Parasitology MA Taylor (2016).

\section{Pengujian Ekstrak Etanol Daun Kemangi Sebagai Anti Skabies}

Berdasarkan hasil pemberian perlakuan, ekstrak etanol daun kemangi menunjukkan rata-rata diameter keropeng yang paling rendah yaitu $(0,62 \mathrm{~mm})$. Selengkapnya disajikan pada Tabel 1. Data diameter keropeng Tabel 1, kemudian analisis data menggunakan uji One Way Anova dan disajikan pada Tabel 2 . 
Tabel 2. Menunjukkan terdapat perbedaan diameter keropeng yang bermakna $(P>0.000)$ antara kelompok perlakuan kontrol negatif (NaCMC $0.5 \%$ ), kontrol positif (Sulfadex), dan perlakuan ekstrak daun kemangi. Untuk mengetahui rata-rata diameter keropeng paling rendah antara ketiga kelompok perlakuan, dilakukan uji lanjut dengan uji Fisher LSD (Least Significance Different).
Tabel 3, menyatakan bahwa diameter keropeng yang paling rendah terdapat pada ekstrak etanol daun kemangi.

3. Perbandingan Kobelum disi Sesudah Perlakuan

Untuk mengetahui secara lebih jelas kondisi marmut yang terinfeksi $S$. scabies, dilakukan pengamatan sebelum dan sesudah permberian perlakuan, hasil disajikan pada Tabel 4.

(c)

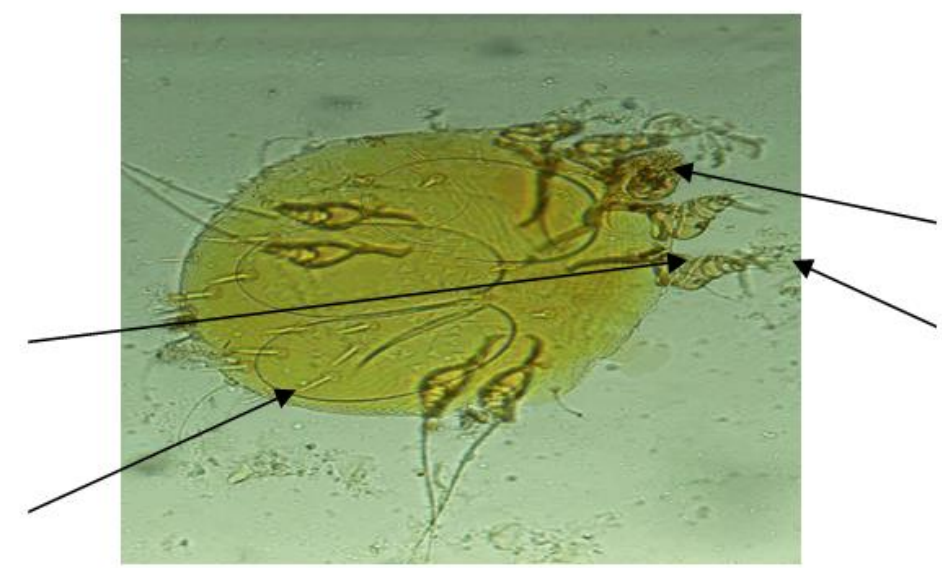

(a)

(b)

Gambar 1. Gambar tungau S. scabiei dengan perbesaran 200x.(a) kepala, (b) pulvilli, (c) kaki, (d) duri.

Tabel 1. Rata-rata diameter keropeng ketiga kelompok perlakuan pada marmut (Cavia porcellus)

\begin{tabular}{cccc}
\hline \multirow{2}{*}{ Ulangan } & \multicolumn{3}{c}{ Diameter Keropeng } \\
\cline { 2 - 4 } & $\begin{array}{c}\text { Kontrol } \\
\text { Negatif }(\mathbf{m m})\end{array}$ & $\begin{array}{c}\text { Kontrol } \\
\text { Positif }(\mathbf{m m})\end{array}$ & $\begin{array}{c}\text { Ekstrak Daun } \\
\text { kemangi }(\mathbf{m m})\end{array}$ \\
\hline 1 & 1,25 & 0,10 & 0,30 \\
\hline 2 & 1,09 & 0,87 & 0,77 \\
\hline 3 & 1,02 & 1,06 & 1,00 \\
\hline 4 & 1,06 & 0,10 & 1,04 \\
\hline 5 & 1,25 & 1,04 & 0,54 \\
\hline 6 & 1,36 & 1,11 & 0,39 \\
\hline 7 & 1,04 & 0,81 & 0,74 \\
\hline 8 & 1,14 & 0,65 & 0,47 \\
\hline 9 & 1,21 & 0,10 & 0,39 \\
\hline Rata-rata & $\mathbf{1 , 1 5}$ & $\mathbf{0 , 6 4}$ & $\mathbf{0 , 6 2}$
\end{tabular}

Keterangan : Kontrol - : Dengan menggunakan NaCMC 0,5 \%, Kontrol+: Dengan menggunakan Sulfadex 
Tabel 2. Uji One Way Anova ekstrak etanol daun kemangi terhadap diameter keropeng pada marmut (Cavia porcellus)

\begin{tabular}{lccccc}
\hline $\begin{array}{c}\text { Sumber } \\
\text { variasi }\end{array}$ & db & JK & MK & $\begin{array}{c}\text { F- } \\
\text { Value }\end{array}$ & $\begin{array}{c}\text { P- } \\
\text { Value }\end{array}$ \\
\hline Perlakuan & 2 & 1,630 & 0,81503 & 8,82 & 0,001 \\
Dalam & 24 & 2,218 & 0,09243 & & \\
\hline Total & 26 & 3,848 & & & \\
\hline
\end{tabular}

Tabel 3. Hasil uji LSD (Least Significance Different)

\begin{tabular}{lll}
\hline Perlakuan & N & Rata-rata \pm StDev \\
\hline K- (NaCMC 0.5 \%) & 9 & $1,1618 \pm 0,1170^{\mathrm{a}}$ \\
$\mathrm{K}+($ Sulfadex) & 9 & $0,651 \pm 0,436^{\mathrm{b}}$ \\
$\mathrm{P}$ (Ekstrak etanol daun kemangi) & 9 & $0,6309 \pm 0,2709^{\mathrm{b}}$
\end{tabular}

Keterangan : Angka yang diikuti dengan huruf superskrip yang berbeda menunjukkan beda nyata dengan Uji LSD (Least Significance Different).

Tabel 4. Perbandingan kondisi keropeng sebelum dan sesudah pemberian perlakuan.

\begin{tabular}{|c|c|c|}
\hline $\begin{array}{l}\text { Kelompok } \\
\text { Perlakuan }\end{array}$ & Sebelum & Sesudah \\
\hline \multicolumn{3}{|l|}{$\mathrm{K}-(\mathrm{NaCMC} 0,5 \%)$} \\
\hline & $\begin{array}{l}\text { Keropeng } \\
\text { Keropeng pada bagian kepala } \\
\text { (Luas }=10,0 \mathrm{~mm})\end{array}$ & $\begin{array}{l}\text { Keropeng pada bagian } \\
\text { kepala (Luas }=17,5 \mathrm{~cm})\end{array}$ \\
\hline \multicolumn{3}{|l|}{$\mathrm{K}+$ (Sulfadex) } \\
\hline & $\begin{array}{l}\text { Keropéng } \\
\text { Keropeng pada bagian telinga } \\
(\text { Luas }=9,50 \mathrm{~mm})\end{array}$ & $\begin{array}{l}\text { Keropeng pada bagian } \\
\text { telinga (Luas }=0.00 \mathrm{~mm} \text { ) }\end{array}$ \\
\hline \multicolumn{3}{|l|}{$\begin{array}{l}\text { P (Ekstrak etanol daun } \\
\text { kemangi) }\end{array}$} \\
\hline & $\begin{array}{l}\text { Keropeng } \\
\text { Keropeng pada bagian telinga } \\
(\text { Luas }=7,50 \mathrm{~mm})\end{array}$ & $\begin{array}{l}\text { Keropeng pada bagian } \\
\text { telinga (Luas }=0.00 \mathrm{~mm} \text { ) }\end{array}$ \\
\hline
\end{tabular}




\section{PEMBAHASAN}

Ditemukannya tungau S. scabiei pada keropeng hasil pemeriksaan mikroskopis (Gambar 6.) diduga disebabkan oleh kondisi lingkungan yang tidak bersih dan tidak terawat. Hal ini sesuai dengan pendapat Djuanda 2010, yang menyatakan bahwa, kondisi lingkungan yang kumuh, dan kebersihan yang buruk dapat menyebabkan tungau $S$. scabiei dapat hidup dan berkembang. Selain kondisi lingkungan yang kurang baik, kondisi kandang juga mempengaruhi adanya tungau $S$. scabiei. Menurut Partosoedjono 2003, kondisi kandang yang kecil akan membuat hewan hidup berdesakan. Dan semakin mempermudah terjadinya penularan pada hewan yang sehat.

Sedangkan pada ekstrak daun kemangi diameter keropeng lebih rendah. Rendahnya diameter keropeng ini diduga karena ekstrak daun kemangi memiliki senyawa aktif yang berperan dalam menghambat proses penularan skabies dapat terjadi melalui kontak langsung dan kontak tidak langsung. Penularan melalui kontak langsung, biasanya terjadi karena adanya gesekan antara hewan penderita. Sedangkan pada kontak tidak langsung penularan terjadi melalui peralatan yang terkontaminasi (Eleser et al, 2005).

Berdasarkan hasil penelitian pada Tabel 3 , dapat dilihat bahwa diameter keropeng pada perlakuan ekstrak daun kemangi memiliki perbedaan dengan diameter keropeng pada perlakuan kontrol negatif (NaCMC 0,5 \%). Pada kontrol negatif diameter keropeng lebih tinggi. Proses pertumbuhan tungau S.scabiei. Senyawa aktif yang terkandung dalam daun kemangi yaitu, flavonoid, saponin, tanin dan minyak atsiri (Novizan, 2002 dan Wijayani, 2014).

Selain flavonoid, saponin dan tanin , pada daun kemangi juga terdapat senyawa lainnya yaitu minyak atsiri. Minyak atsiri pada daun kemangi tersusun dari senyawa aktif berupa eugenol dan methyl clavical yang berfungsi sebagai larvasida (Dattu et al, 2008).
Berdasarkan pengamatan kondisi marmut sebelum dan sesudah (Tabel 4.) dapat dilihat bahwa pada pemberian perlakuan ekstrak daun kemangi dan kontrol positif (sulfadex) menunjukkan diameter keropeng menjadi lebih rendah sesudah diberikannya perlakuan. Rendahnya diameter keropeng pada ekstrak daun kemangi, diduga karena adanya kandungan eugenol yang berperan dalam proses penyembuhan diameter keropeng. Karena, eugenol memiliki kemampuan sebagai antiparasit dan antioksidan pada daun kemangi. Mekanisme kerja yaitu dapat menyebabkan alergi apabila terpapar pada kulit. Menurut Dattu et al 2008, pada dosis tinggi eugenol dapat mengakibatkan efek seperti terbakar. Hal ini yang mengakibatkan kematian larva dan bentuk fisik larva terlihat seperti terbakar. Eugenol juga bekeja pada sistem syaraf, karena eugenol merupakan senyawa fenol yang memiliki gugus alkohol sehingga dapat melemahkan dan mengganggu sistem syaraf.

Pada perlakuan kontrol negatif ( $\mathrm{NaCMC} \quad 0,5 \%$ ) diameter keropeng menjadi lebih tinggi (Tabel 4.). Karena pemberian $\mathrm{NaCMC} \quad 0,5 \%$ pada keropeng tidak memberikan pengaruh terhadap proses kesembuhan keropeng, selain itu NaCMC 0,5\% tidak memiliki kandungan zat yang dapat menyembuhkan keropeng akibat skabies. Apabila tidak diobati, tungau berhasil masuk kedalam kulit dan menyebabkan timbulnya rasa gatal serta adanya ruam pada kulit. Ruam pada kulit terjadi akibat adanya penonjolan kulit tanpa berisi cairan, berbentuk bulat, berbatas tegas, berwarna merah, ukuran $<1 \mathrm{~cm}$ yang terus berkembang sehinggi berisi nanah. (McCarthy, et al, 2004). Ciri marmut yang terinfeksi tugau S.scabiei yaitu marmut akan merasa gatal dan menggesekkan tubuhnya ke kadang. $\mathrm{Hal}$ ini sesuai dengan pendapat Colleville 2000, yang menyatakan, apabila marmut terinfeksi S.scabiei, marmut akan menggesek-gesekan bagian tubuh yang gatal pada dinding kandang, mencakar ataupun menggaruk dan menggigit kulitnya 
secara terus menerus sehingga menyebabkan melebarnya keropeng.

\section{KESIMPULAN}

Berdasarkan hasil penelitian dapat disimpulkan bahwa ekstrak daun kemangi (Ocimum sanctum) memiliki kemampuan sebagai anti skabies pada mamrmut (Cavia porcellus).

\section{SARAN}

Perlu dilakukan penelitian mengenai pengaruh ekstrak daun kemangi (Ocimum sanctum) terhadap kepadatan tungau Sarcoptes scabiei. pada marmut (Cavia porcellus).

\section{DAFTAR PUSTAKA} J. 2000

Diagnost Parasitology for Veterinary Technicians.American.

Djuanda, A. 2010. IImu Penyakit Kulit dan Kelamin. Edisi Kelima. FK UI. Jakarta.

Dattu Iffah $H$, Dwi Jayanti G, Agus Kardinan. 2008. Pengaruh Ekstrak Kemangi (Ocimum basilicum forma ciratum) Terhadap Perkembangan Lalat Rumah (Musca domestica) (L.). Journal Entomol Indon. 5 (1):36-44.

Eleser, S., Junjungan, J.,Manurungdan T., Suibu. 2005. Efektivitas pemberian monolaurin dan obat alternative lainnya dalam memberantas penyakit scabies pada kambing. Pros. Seminar

Nasional Peternakan dan Teknologi Veteriner, Bogor, 12-13 September 2005. Puslitbang, Peternakan, Bogor. 941-945.

McCarthy, JS, Kemp, D, dan Currie, BJ. 2004. Scabies : More Than Just An Irritation. Postgraduate Medical Journal. 80:382-387

Novizan. 2002. Membuat dan Memanfaatkan Pestisida Ramah Lingkungan. Jakarta: Agromedia Pustaka, hh: 37-40.

Partosoedjono, S. 2003. Scabies dan Kualitas Sanitasi Masyarakat.
Kompas, Jumat, 05 September 2003. 65-70. 2005.Puslitbang Peternakan, Bogor. 941-945.

Prakash P. and Gupta N., 2005, Therapeutic uses of Ocimum ctum Linn (Tulsi) with a note on eugenol and its pharmacological actions: A short review, Indian Journal of Physiology and Pharmacology, 49 (2), 125-131.

Taylor, M.A., Coop, R.L., Wall, R.L., 2016. Veterinary Parasitology, $4^{\text {th }}$ Edition. Wiley Blackwell. UK: 221.

Wijayani LA, 2014. Efek Larvasidal Ekstrak Etanol Daun Kemangi (Ocimum sp. Linn) Terhadap Larva Instar III Culex quinquefasciatus. Universitas Islam Indonesia, Jakarta. 